\title{
High aspect ratio air core solenoid inductors using an improved UV-LIGA process with contrast enhancement material
}

Hong Lu · Brandon Pillans · Jong-Chan Lee •

Kyunghwan Kim $\cdot$ Jeong-Bong Lee

Published online: 25 August 2006

(C) Springer-Verlag 2006

\section{Erratum to: Microsyst Technol DOI 10.1007/s00542-006-0174-3}

Unfortunately, the author Kyunghwan Kim was omitted in the original version of this article. His name and affiliation are shown here.

K. Kim

Department of Electric and Information Engineering, Kyungwon University, Seongnam, South Korea

The online version of the original article can be found at http://dx.doi.org/10.1007/s00542-006-0174-3.

H. Lu $(\varangle) \cdot$ B. Pillans $\cdot$ J.-C. Lee $\cdot$ J.-B. Lee

Department of Electrical Engineering,

University of Texas at Dallas,

Richardson, TX 75083, USA

e-mail: luhm@utdallas.edu

K. Kim

Department of Electric and Information Engineering,

Kyungwon University, Seongnam, South Korea 